\title{
Documento de la I Jornada Estatal
}

de Renovación Pedagógica

Reunidos en Almagro (Ciudad Real) los delegados de las Escuelas de Verano y entidades pedagógicas que se relacionan al pie de este documento, acuerdan hacer públicas y difundir las siguientes consideraciones.

\section{1.- REFLEXION PREVIA EN \\ TORNO A LA RENOVA. CION PEDAGOGICA}

1) Las Escuelas de Verano y los movimientos de renovación pedagógica se consideran como entidades abiertas a la reflexión, a la crítica de la problemática educativa y a la elaboración de objetivos de trabajo para todos los enseñantes que deseen transformar la escuela.

2) La reflexión y el esfuerzo de muchos enseñantes ha conducido a elaborar una alternativa global a la enseñanza, a una profundización del proyecto de reforma escolar. En la dirección del objetivo de una Escuela Pública como superadora de los conceptos actuales de escuela estatal/escuela privada, se plantea hoy la urgente necesidad de elaborar los contenidos pedagógicos, los métodos didácticos $y$ las lineas de trabajo educativo que vengan a llenar de sentido $y$ ? validez a ese planteamiento general.

3) A pesar de las condiciones diferentes, de la diversidad de medios y de la heterogeneidad de las escuelas de verano, cabe señalar como elementos comunes, su voluntad de producir un cambia progresista en la estructura escolar, y, de otra parte, su intención de integrar la escuela a la comunidad cultural y al medio en la que se sitúa. Para ello, se considera imprescindible una formación del enseñante que escape tanto de un planteamiento dogmático y general como de un detallismo pedagogis ta. Se pretende dar al enseñante todos los elementos que precise para facilitar su tarea profesional y su conciencia de agente de cambio cultural y social.
4) Las escuelas de verano y otros grupos de renovación pedagógica, por su mismo carácter abierto y unitario, se dirigen especialmente a la formación del enseñante. Se constata, también, la oportunidad de dirigirse asimismo a los padres $y$, en su caso, a los alumnos. La escuela sólo podrá transformarse con la colaboración y el consenso de todos.

Se señala como objetivo esencial de las escuelas de vera no y demás organismos, el de dar permanencia a su organización y continuidad a su tarea de reflexión, investigación, intercambio y publicación de resultados. Creación de grupos de trabajo, de seminarios o equipos que funcionen a lo largo del año y que, a su vez, enriquezcan las jornadas de verano.

6) La estructura, organización $y$ concepción de las $E_{\text {。 de }}$ $V$. debería superar las formas de relación de la enseñanza tradicional buscando formas de trabajo acordes con los principios de renovación activa de la pedagogía

\section{II.- COORDINACION E IN- TERCAMBIO}

1). En base a esos principios y reflexiones comunes y con la consideración previa de la autonomía de cada Escuela de Vera. no u otras iniciativas pedagógicas de carácter progresista, inicialmente se cree necesaria una cierta coordinación entre ellas. No se trata de crear superestructuras burocráticas, sino por el contrario de facilitar el máximo desarrollo de cada colectivo $y$ establecer formas ágiles $y$ positivas de contacto e información mutuos.

2) Esa necesidad de coordinación ha sido concretada durante estas Jornadas, en los aspectos siguientes.

1.- Elaboración de un archivo sistematizado de todas las actividades, profesorado, recursos, publicaciones, experiencias, materiales y otros aspectos que giren en torno a cada unia de las Escuelas de Verano.

b. - Intercambio regular de la documentación, informes $y$ publicaciones que cada colectivo produzca.

confrontación de experiencias, elaboración de actividades específicas como programas, temas de interés común, intercambio de cursos, etc.

d.- Elaboración de una actuación común, en las relaciones con la Administración para el reconocimiento legal de cada colectivo y la gestión de los recursos económicos necesarios.

\section{III.- RELACION CON OTROS ORGANISMOS}

1).- Para la consecución de los objetivos reseñados y por encima de las diferentes situaciones de cada colectivo de Renovación Pedagógica y de su contexto propio, en estas las Jornadas se han señalado como características comunes la independencia de actuación, el pluralismo y la apertura hacia todas las entidades y personas que estén por un auténtico cambio de las prácticas pedagógicas $\vee$ de la estructura escolar en la dirección de la Escuela Pública.

2) Se señala, en este sentido, el interés y la importancia de establecer $y$ mantener una relación abierta, siempre que sea conservando esa autonomía y $\sin$ abandonar los objetivos señalados, en instituciones tales como Universidades, Insitutos de Ciencias de la Educación, Delegaciones del Ministerio de Educación, Inspección, Ministerio de Cultura y otras similares. Se señala la necesidad de coordinarse estructuralmente con los Colegios de Doctores y Licenciados, Escuelas de Formación del Profesorado, Colectivos de Psicólogos Escolares, etc., a fin de impulsar integradamente la renovación escolar en su conjun. to.

3) Ante el nuevo contexto político se pone de relieve la necesidad de implicar y de recabar la colaboración en la or ganización de las E. de Verano de las Entidades Autonòmicas, de los Ayuntamientos $y$ de todas aquellas entidades locales, públicas o privadas, que permitan ampliar el eco y la provección pública de los grupos pedagógicos que actủan con una óptica renovadora.

4).- En esta tarea de transformación de la escuela se debe obtener también la colaboración la participación y el apoyo de las Asociaciones de Padres, de Alumnos, Asociaciones de profesionales relacionados con la educación y la cultura de todos los organismos que se hagan portadores y defensores de los principios específicos de renovación escolar y social.

\section{IV.-PROPUESTA A DEBATE}

1) A fin de recoger el máximo posible de criterios con los que asentar la Revonación Pedagógica $y$ de dotarse de formas de organización, estas las jornadas proponen:

a.- Que cada E. de V. se organicen actividades específicas para informar del desarrollo de estas jornadas.

b.- Que sea elegido un miembro organizador de cada E. de V. o representantes de cada colectivo pedagógicos, para que asuma la responsabilidad de sintetitzar el resultado de tales debates, de enviar a cada delegación presente los materiales para que puedan establecer el fichero, mantener todos los contactos sobre el tema, etc.

Por último se propone que, con toda la información acumu lada $\vee$ las propuestas de trabajo Y de coordinación se vaya a la celebración de unas II Jornadas. A propuesta de la representación de la E. de V. de Aragón, la sede puede ser Jaca (Aragón), antes del próximo año.

En Almagro, a 30 de abril de 1.979 . 